\title{
Differences in proportion and dynamics of recipient hematopoiesis following hematopoietic cell transplantation in CML and IMF
}

\author{
UDO SIEBOLTS $^{1,5}$, JÜRGEN THIELE ${ }^{1}$, THOMAS ZANDER ${ }^{4}$, MARKUS DITSCHKOWSKI $^{3}$, \\ DIETRICH W. BEELEN ${ }^{3}$, NICOLAUS KRÖGER ${ }^{2}$, BORIS FEHSE ${ }^{2}$ and CLAUDIA WICKENHAUSER ${ }^{1}$
}

\begin{abstract}
${ }^{1}$ Institute of Pathology, University of Cologne, Kerpener Str. 62, D-50924 Cologne; ${ }^{2}$ Department of Bone Marrow Transplantation, University Hospital Hamburg, D-20246 Hamburg; ${ }^{3}$ Department of Bone Marrow Transplantation, University Hospital of Essen, Hufeland Str. 55, D-45122 Essen; ${ }^{4}$ Molecular Tumor Biology and Tumor Immunology, Clinic I for Internal Medicine, University of Cologne; ${ }^{5}$ Center for Molecular Medicine, University of Cologne (CMMC), Kerpener Str. 62, D-50924 Cologne, Germany
\end{abstract}

Received August 16, 2007; Accepted September 26, 2007

\begin{abstract}
Since decades myeloablation followed by allogeneic stem cell transplantation offered the only opportunity to cure leukemia patients and only recently the development of STI571 created a further alternative in chronic myeloid leukemia (CML). While among all leukemias this transplantation regimen had the best outcome in CML, trials with reduced intensity conditioning regimens (RIC) were rather humbling and recurrence of the neoplastic clone occurred frequently. However, the same therapy in patients with idiopathic myelofibrosis (IMF) resulted in a more favorable outcome. Therefore, long-term mixed chimerism $(\mathrm{mCh})$ was determined on bone marrow (BM) biopsies derived from five IMF patients and from eight CML patients of the pre STI era following sex-mismatched transplantation. All patients presented lasting hematologic remission and were matched concerning age, sex and appearance of GvHD. Analysis of late transplant period $($ day +100$)$ revealed a concentration of host cells within the $\mathrm{CD} 34^{+}$precursor cell compartment in both diseases. However, in IMF BM biopsies only up to $8 \%$ recipient $\mathrm{CD}_{3} 4^{+}$precursors but in CML biopsies up to $26 \%$ recipient $\mathrm{CD} 4^{+}$precursors were detected. Taken into account that in CML up to $10 \%$ of the host $\mathrm{BM} \mathrm{CD} 34^{+}$ precursors bear the BCR-ABL translocation our data suggest that the neoplastic $\mathrm{CD} 34^{+}$progenitor cell population might dispose of better strategies to escape immune surveillance in CML than in IMF.
\end{abstract}

Correspondence to: Dr Claudia Wickenhauser, Institute of Pathology, University of Cologne, Kerpener Str. 62, D-50924 Cologne, Germany

E-mail: c.wickenhauser@uni-koeln.de

Key words: chronic myeloproliferative disease, chronic myeloid leukemia, reduced intensity conditioning, graft-versus-leukemia, mixed chimerism, FISH, CD34+ ${ }^{+}$progenitors

\section{Introduction}

Allogeneic bone marrow and hematopoietic stem cell transplantation (allo-BMT/HSCT) has arguably been applied successful in the treatment of chronic myeloid leukemia (CML) and still remains the most effective strategy for inducing durable molecular remission in STI571 (imatinib mesylate, Gleevec) refractory patients $(1,2)$. The application of conventional myeloablative allo-HSCT has, amongst others, been limited by the age of the recipient. Therefore, the use of reduced intensity conditioning (RIC) regimen was studied in a limited number of patients. However, even if some published data remain contradictory most studies reported an elevated risk for recurrence of the disease and an adverse outcome $(1,3,4)$. Idiopathic myelofibrosis (IMF), a less common chronic myeloproliferative disease (CMPD) with an onset in the elderly, carries a prognosis with a median survival of four years $(5,6)$. Initial studies on a small number of patients demonstrated that conventional myeloablative therapy lead to high transplant-related mortality (7-10). However, the use of RIC resulted in a better outcome in IMF patients (11). In general, the elimination of tumor cells is mostly due to a strong graft-versus-leukemia (GVL) effect of the donor alloimmune effector lymphocytes (12-14). When leukemia relapses after allogeneic hematopoietic cell transplantation (HCT), donor lymphocyte transfusions can induce sustained remissions in some patients (15). The different response of IMF and CML patients on above-mentioned therapy regimen could suggest that neoplastic hematopoiesis in CML might dispose of better escape strategies than hematopoiesis in IMF.

\section{Patients and methods}

Patients (IMF). A total of five patients (four men, one woman; mean age 45 years, fifteen sequential post-transplant trephine biopsies) with IMF in the chronic phase of the disease received PBSC grafts from sex-mismatched HLA identical family 
donors at the University Hospital Hamburg, Germany. All patients had a history of various therapeutic regimens including hydroxyurea, busulfan as well as radiation or a combination of these. All patients received standardized RIC with busulphan $(10 \mathrm{mg} / \mathrm{kg})$, fludarabine $\left(180 \mathrm{mg} / \mathrm{m}^{2}\right)$ and anti-thymocyte globulin followed by allo-HSCT with a median number of transplanted $\mathrm{CD} 34^{+}$progenitors of $8 \times 10^{6}$ per $\mathrm{kg}$ body weight (range 0.9-15.6). No primary graft failure occurred. The median time until leukocyte $\left(>1.0 \times 10^{9} / 1\right)$ and platelet $(>20 \mathrm{x}$ $10 \% / 1$ ) engraftment was 16 (range, 11-26) and 23 days (range, 9-139) respectively. Acute graft-versus-host disease (GvHD) grade II-III occurred in three patients and two patients had limited chronic GvHD. Standard GvHD prophylaxis was performed (MTX + Cyclosporin A). Hematological response and complete histopathological remission without signs of relapse was seen in all five patients during the period under consideration. The patients were enrolled in a prospective pilot study of RIC. Explicit approval of this study was obtained from the local ethics committee and all patients gave written informed consent (see also refs. 11 and 16).

Patients (CML). Sixteen archived pre- and post-transplant BM biopsies (1985-1996) of eight patients from the pre-STI era (five men and three women, median age 37 years) with chronic phase CML were enrolled in the study. Patients had received BM grafts (median size $2.3 \times 10^{8} / \mathrm{kg}$ nucleated cells) from sexmismatched HLA identical family donors at the University Hospital of Essen, Germany, following standard procedures that included conditioning regimens (Cy $60 \mathrm{mg} / \mathrm{kg} / \mathrm{day}$ x 2; dose of total body irradiation (TBI) 4 x 2.5 Gy cobalt-60 and GvHD prophylaxis (MTX + Cyclosporin A). A successful engraftment according to standard criteria was established at day $24 \pm 5$ in all patients $(17,18)$. Acute GvHD grade II-III developed in five patients and limited chronic GvHD was diagnosed in three patients. All patients presented complete hematologic remission for the period under study. Blood analysis revealed cytogenetic remission in the whole period under study (19).

$B M$ biopsies. BM trephine biopsies were performed from the posterior iliac crest. The fixation of samples was carried out in a low-concentrated phosphate-buffered formalin solution for $12-48 \mathrm{~h}$. Further processing included decalcification for 3-4 days in $10 \%$ buffered ethylene-diamine tetra-acetic acid (EDTA), pH 7.2, paraffin wax embedding, and employment of several staining techniques, involving Giemsa, PAS (periodic acid Schiff reagent), naphthol-AS-D-chloroacetate esterase, Perls' reaction for iron and a silver impregnation method (Gomori's technique).

Sequential immunostaining and dual color fluorescence in situ hybridization (FISH). For a simultaneous immunophenotypic and genotypic evaluation, $4 \mu \mathrm{m}$ paraffin-embedded sections

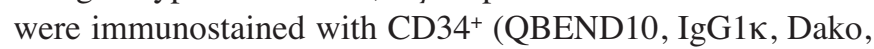
Hamburg, Germany), or CD61+ (Y2/51, IgG1к, Dako). Subsequently, the slides were incubated with a satellite probe mix for chromosomes $x$ and $y$ (CEP $X$ Spectrum Orange/CEP Y Spectrum Green DNA Probe Kit; Vysis, Bergisch Gladbach, Germany) as described previously (20).
The slides were evaluated with an Aristoplan microscope (Leitz, Wetzlar, Germany) equipped with an optimized triple bandpass filter and imaged with a digital camera (Photometrics SenSys; Tucson, AZ, USA) and appropriate software (IPLab Spectrum P, Vienna, VA, USA). Only those cells containing exactly two marked signals were evaluated.

Polymerase chain reaction $(P C R)$ analysis. Quantitative Y chromosome-specific PCR assay (QYCS-PCR) based on the DFFRY gene for the determination of hematopoietic donor chimerism was performed on peripheral blood cells of four male IMF patients as formerly described $(11,16)$. This method can be used to detect remaining male cells after sexmismatched allogeneic blood stem cell transplantation (HSCT) involving a male patient and female donor (16). For PCR, primers FP-Y (aactcacctccaacacatactccac) and RP-Y (ttcatgatgaaatctgctttttgttt) were synthesized according to the published sequence of the DFFRY gene (21). A FAMlabeled TaqMan probe (P-Y, cagccaccagaattatctccaagctct ctga) was designed using Primer Express software to allow real-time quantitative PCR in an ABI PRISM 7700 Sequence Detection System (Applied Biosystems, Weiterstadt, Germany). To standardize DNA content, a second PCR reaction detecting the human hematopoietic cell kinase gene HCK was carried out in the same tube (multiplex) $(22,23)$.

Male (Y chromosome-positive) cell content was quantified based on ct (threshold cycle) values obtained after real-time PCR. Statistical data evaluation was performed with Microsoft Excel software (16).

\section{Results}

Validation of polymerase chain reaction and fluorescence in situ hybridization. Serial dilutions of male mononuclear cells in female cells confirmed that the detection of $<1$ male in 100,000 female cells $(<0.001 \%)$, was possible. Concerning the female patient in this collective, the Y chromosome-specific PCR was negative.

In all patients dual color FISH was performed on pretreatment trephine biopsies to validate the method. Concerning the male patients, in $0.3 \%$ cells the genotype was spuriously suggested to be female while a total congruence with the female gender was found in all cells under investigation.

Distribution of donor and host hematopoiesis in BM and PB. Concerning the four male IMF patients $\mathrm{mCh}$ was verified to be a phenomenon affecting both, the BM and the PB compartment. In detail, QYCS-PCR data demonstrated a proportion of $\mathrm{PB}$ recipient cells ranging between 0 and $1 \%$ in the early as well as late post-transplant period. Concerning analysis of corresponding sequential BM biopsies and FISH examination 0 and $1 \%$ host megakaryocytes were seen in the early post-transplant period and also at day +100 , respectively. In contrast, $\mathrm{BM} \mathrm{CD} 34^{+}$progenitors displayed a host cell proportion of 5 and $8 \%$ by examination of the early transplant period and day +100 , respectively. The variation in host cell distribution concerning early and late post-transplant period, however, was not statistically significant (t-test; unpaired).

Evidence of constitutive BM host hematopoiesis in CML patients with lasting cytogenetic remission in $P B$. MCh of 
Table I. Portion of Graft and Host hematopoiesis of early and late transplant phase.

\begin{tabular}{|c|c|c|c|c|}
\hline & \multicolumn{2}{|c|}{ Day $\leq 100$ after HCT } & \multicolumn{2}{|c|}{ Day $\geq 101$ after HCT } \\
\hline & Host (\%) & Graft $(\%)$ & Host $(\%)$ & Graft $(\%)$ \\
\hline \multicolumn{5}{|l|}{ IMF } \\
\hline Progenitor cells (CD34) & $6 \quad(5)$ & $109(95)$ & $11 \quad(8)$ & $135(92)$ \\
\hline Megakaryocytes (CD61) & $0 \quad(0)$ & $182(100)$ & $3 \quad(1)$ & $222(99)$ \\
\hline \multicolumn{5}{|l|}{ CML } \\
\hline Progenitor cells (CD34) & $19(18)$ & $89(82)$ & $30(26)$ & $84(74)$ \\
\hline Megakaryocytes (CD61) & $8(11)$ & $65 \quad(89)$ & $10(13)$ & $70(87)$ \\
\hline
\end{tabular}

Portion of graft and host hematopoiesis of early and late transplant phase. Pooled data of five IMF patients and eight CML patients following FISH analysis and immunohistochemistry for CD34 of CD61 are demonstrated. Counted cells and parenthesized percentage for graft and host hematopoiesis of early and late transplant phase are presented. (Total no. of counted cells: 1043).
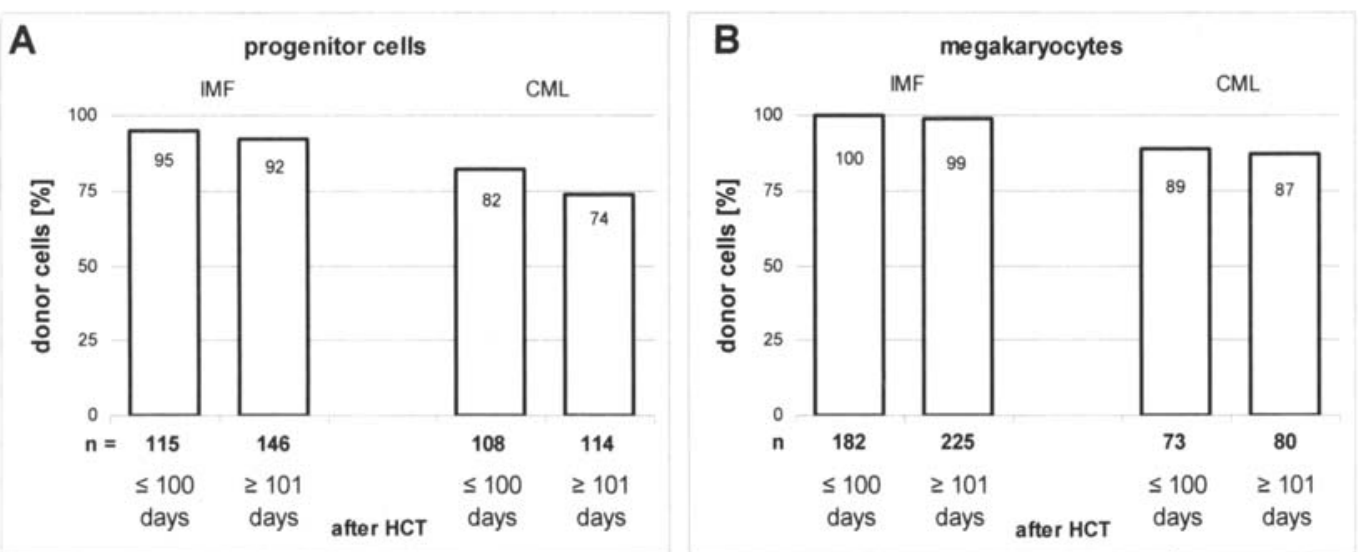

Figure 1. MCh in IMF and CML following HCT. Rate of donor cells for the time-points of early ( $\leq 100$ days) and late ( $\geq 101$ days) post-transplant period (n, number of counted cells). CD34+ progenitors (A) and megakaryopoiesis (B)

post-transplant BM biopsies exclusively derived from patients with lasting cytogenetic remission was analysed. In all cases under study a distinct proportion of host derived hematopoietic cells was seen. Detailed FISH analysis of megakaryocytes as an element of mature hematopoiesis revealed $\mathrm{mCh}$ of $11 \%$ in the early post-transplant period and of $13 \%$ at day +100 . Concerning the $\mathrm{CD}_{34}{ }^{+}$progenitors 18 and $26 \%$ were of host origin when examining BM biopsies of the early posttransplant period and day +100 , respectively. These data indicate the presence of a lasting BCR-ABL negative host cell hematopoiesis in disease-free post-transplant CML patients. Observed variations of host cell distribution in early and late post-transplant period were not statistically significant for the megakaryocyte or for the CD $34^{+}$ progenitor cell compartment.

MCh is particularly a phenomenon of the immature hematopoiesis. To compare $\mathrm{mCh}$ in mature and the immature hematopoiesis $29 \mathrm{BM}$ biopsies of $5 \mathrm{IMF}$ and $8 \mathrm{CML}$ patients were analysed. In both diseases a higher proportion of host derived $\mathrm{CD} 34^{+}$progenitors was seen when compared to megakaryocytes. In detail, concerning the early post-transplant period, $5 \%$ of the $\mathrm{CD} 34^{+}$progenitors but no megakaryocytes were of host origin in IMF patients while $18 \%$ of the $\mathrm{CD}^{3} 4^{+}$ progenitors and $11 \%$ of the megakaryocytes were of host origin in CML. Concerning day $+100,8 \%$ host $\mathrm{CD}_{3} 4^{+}$ progenitor cells but only $1 \%$ host megakaryocytes were seen in IMF and in CML mCh represented $26 \%$ of the CD34 progenitors and $13 \%$ of the megakaryopoiesis. The prominent role of $\mathrm{CD}_{3} 4^{+}$progenitors in $\mathrm{mCh}$ was seen in all patients Concerning the IMF patients this finding was statistically significant by unpaired t-test for both time periods. Concerning the CML patients results were marginally not significant but disclosed the same trend.

Superior bone marrow $m$ Ch in CML compared to IMF. FISH analysis of 1043 hematologic cells derived from BM biopsies of IMF and CML patients in hematological remission revealed a constant higher proportion of host derived megakaryopoiesis and $\mathrm{CD} 34^{+}$progenitors in CML patients. This phenomenon was observed in early as well as in late posttransplant period. As summarized in Table I in IMF patients complete chimerism of the $\mathrm{CD} 61^{+}$megakaryopoietic lineage was obtained within the first 100 days. At all later time- 
points the fraction of recipient cells in this cell lineage was below $2 \%$. In the group of CML patients $11 \%$ of the megakaryocytes were of host origin in the early posttransplant period while mCh was $13 \%$ at day +100 (Table I; Fig. 1).

When data for the $\mathrm{CD} 34^{+}$cell population of $\mathrm{CML}$ patients were compared to those of the IMF patients the contingent of recipient cells was significantly elevated in the CML group in the early as well as the late post-transplant period ( $\mathrm{p}<0.05$; t-test; unpaired) (Table I; Fig. 1).

\section{Discussion}

QYCS-PCR is a rapid and sensitive technique to detect male cells and therefore enables analysis and quantification of $\mathrm{PB}$ $\mathrm{mCh}$ in sex mismatched HCT $(16,24,25)$. A disadvantage of this method is the constriction on male patients. In the analysis of BM biopsies, recipient stromal cells cannot be differentiated from host hematopoiesis and therefore the changing relation between hematopoiesis and stromal cells during the engraftment and post-transplant period falsifies the results. In the evaluation of BM biopsies the FISH technique therefore outmatches the QYCS-PCR technique. In combination with immunohistochemical analysis this assay allows the genotyping of single phenotyped cells. Assuming that in CMPD the source of relapse probably is the undifferentiated hematopoietic progenitor cell FISH analysis also is an important tool in monitoring hematopoietic engraftment in the BM after transplantation (26).

Following a gender-mismatched transplantation, the concurrent characterization of genotype and cell lineage provides suitable means for the identification of chimeric states and thus the host/donor origin of a certain cell population (24). However, it has to be considered that the number of host cells does not necessarily reflect the number of neoplastic hematopoiesis $(17,18,20)$ and the relevance of host cell number on HCT outcome remains controversial (27-30). Analyzing the same BM biopsies, we reported a BCR/ABL positive population within the $\mathrm{CD} 34^{+}$cell compartment ranging from 5 to $10 \%$ (18) indicating that $30-50 \%$ of the host $\mathrm{CD} 34^{+}$cells bear the translocation. These data indicate that an increase in $\mathrm{mCh}$ indeed is a powerful indicator of initial relapse and therefore an important tool to initialize accurate treatment as soon as possible (31). In IMF our data also indicate that measurement of $\mathrm{mCh}$ is a useful and true instrument in the monitoring of clonal diseases when a defined chromosomal aberration is unknown $(7,8,32,33)$.

In this study the FISH technique was applied to compare and monitor IMF and CML patients transplanted with sexmismatched donors. Combination of FISH technique with IHC allowed subdivision of maturing and immature hematopoiesis. In this context $\mathrm{CD} 1^{+}$megakaryopoiesis lineage was selected because, based on previous data, the probability to detect single recipient cells in these lineage is higher when compared with those of the erythro- and granulopoiesis presumably by virtue of the polyploid state of these cells (17). The immature, potentially dormant hematopoiesis was detected by CD34 IHC. Morphological control of the stained cells within the BM allowed a clear discrimination from CD34 endothelial cells because BM vessels were omitted in the evaluation (18).
With CML and IMF two CMPD were selected which are both hematopoietic stem cell diseases. Although a specific chromosomal aberration is only described in CML this disease shares a lot of clinical and morphological similarities with IMF. A maximum similarity in both groups was achieved as follows: i) patients were matched concerning age, phase of their disease and risk of GvHD; ii) only patients in lasting complete hematologic remission were elected; and iii) patients achieved grafts from sex-mismatched HLA identical family donors. In addition, only CML patients in complete cytogenetic remission were elected. Differences in the management of both diseases included i) the manner of hematopoietic eradication (myeloablation in the CML group versus myeloreduction via RIC in the IMF group) and ii) the manner of transplantation (allo-BMT in the CML group versus alloHSCT in the IMF group) and resulted from the adverse outcome of the therapy concerning the setting vice versa $(1,3,7-11)$. Concerning the time-points day +100 posttransplant, however, effects of initial therapy (allo-BMT and allo-HSCT) are blurred because at that time-point the interplay between immune reactivity of the graft and immunogenity of the tumor cells is regarded to be essential for the course of the individual disease $(19,34)$. In addition, individual ranges of the relative proportion of T-cells are indeed broad but are reported not to differ between BM and peripheral blood stem cell allografts (35).

In both diseases under study $\mathrm{mCh}$ was concentrated within the population of $\mathrm{CD} 34^{+}$progenitors. Assuming that the majority of neoplastic cells are comprised in this compartment our data are in line with the findings that early leukemia relapse is indicated by sequential monitoring of $\mathrm{mCh}$ in $\mathrm{PB}$ CD34+ cells (36). Concerning CML, the prominent role of $\mathrm{BM} \mathrm{CD} 34^{+}$cells is further highlighted by the finding of constant persistence of malignant hematopoietic progenitors in patients in complete PB cytogenetic remission (18). Although a direct comparison was not conducted it is likely that these findings affect $\mathrm{CD} 34^{+}$progenitors from both sources, $\mathrm{PB}$ and $\mathrm{BM}$, respectively.

The most prominent difference between IMF and CML $\mathrm{BM}$ findings was the significantly elevated rate of $\mathrm{mCh}$ in CML hematopoiesis. These data indicate that host CD34 cells and therefore also primary neoplastic stem cells in CML seem not to be as sensitive to myeloreductive drugs and, even more important, to graft versus leukemia reactions than their counterparts in IMF. In other words, the presented data indicate that the interplay between reduction of the host cell mass and efficiency of the unedited donor immune system in eradication of host and tumor cells has to be linked to each disease and disease stage. An excess of tumor mass over each individual threshold therefore leads to uncontrolled proliferation of the neoplastic progenitors, an observation that can be underlined by previously published FISH data on sequential trephine biopsies of relapsing CML patients $(17,18)$. The finding that myeloablative regime may not be sufficient to cure CML at least in advanced disease, points to the same direction $(3,37,38)$.

In this context, allowing the assumption that immunological responses against tumor cells are likely to be most effective against the most immunogenic of the tumor cell population and least effective against the escape mutants that 
have evolved various means of camouflage or resistance for immune mediated toxicity (37). Our present data indicate that $\mathrm{CML} \mathrm{CD} 34^{+}$progenitors are more resistant and harder to eradicate than their IMF counterparts. This, in part, could depend on the low translation of immunogenic BCR-ABL protein by $\mathrm{CML} \mathrm{CD} 34^{+}$progenitor cells (34). However, the concomitant higher fraction of recipient megakaryopoiesis in CML patients bearing large amount of $\mathrm{BCR}-\mathrm{ABL}$ protein indicates that this might not be a major reason for the less complete eradication. Altogether, our findings support the conclusion that neoplastic hematopoiesis in IMF patients might be more vulnerable to immunological responses than the neoplastic $\mathrm{CD} 34^{+}$progenitor cell population in $\mathrm{CML}$ patients perhaps due to better strategies in escaping immune surveillance of the latter. Further studies will have to clarify which GVL target antigens could be responsible for the more effective strategies of $\mathrm{CML} \mathrm{CD} 34^{+}$progenitors to escape immune surveillance.

\section{Acknowledgements}

Supported by a grant from the Dr. Mildred Scheel Foundation for Cancer Research (No. 106324).

\section{References}

1. Crawley C, Szydlo R, Lalancette M, Bacigalupo A, Lange A, Brune M, Juliusson G, Nagler A, Gratwohl A, Passweg J, Komarnicki M, Vitek A, Mayer J, Zander A, Sierra J, Rambaldi A, Ringden O, Niederwieser D and Apperley JF: Outcomes of reduced-intensity transplantation for chronic myeloid leukemia: an analysis of prognostic factors from the Chronic Leukemia Working Party of the EBMT. Blood 106: 2969-2976, 2005.

2. Goldman JM and Druker BJ: Chronic myeloid leukemia: current treatment options. Blood 98: 2039-2042, 2001.

3. Sloand E, Childs RW, Solomon S, Greene A, Young NS and Barrett AJ: The graft-versus-leukemia effect of non-myeloablative stem cell allografts may not be sufficient to cure chronic myelogenous leukemia. Bone Marrow Transplant 32: 897-901, 2003.

4. Or R, Shapira MY, Resnick I, Amar A, Ackerstein A, Samuel S, Aker M, Naparstek E, Nagler A and Slavin S: Non-myeloablative allogeneic stem cell transplantation for the treatment of chronic myeloid leukemia in first chronic phase. Blood 101: 441-445, 2003.

5. Barosi G and Hoffman R: Idiopathic myelofibrosis. Semin Hematol 42: 248-258, 2005.

6. Reilly JT: Idiopathic myelofibrosis: pathogenesis to treatment. Hematol Oncol 24: 56-63, 2006.

7. Rondelli D, Barosi G, Bacigalupo A, Prchal JT, Popat U, Alessandrino EP, Spivak JL, Smith BD, Klingemann HG, Fruchtman S and Hoffman R: Allogeneic hematopoietic stemcell transplantation with reduced-intensity conditioning in intermediate- or high-risk patients with myelofibrosis with myeloid metaplasia. Blood 105: 4115-4119, 2005.

8. Deeg HJ, Gooley TA, Flowers ME, Sale GE, Slattery JT, Anasetti C, Chauncey TR, Doney K, Georges GE, Kiem HP, Martin PJ, Petersdorf EW, Radich J, Sanders JE, Sandmaier BM, Warren EH, Witherspoon RP, Storb R and Appelbaum FR: Allogeneic hematopoietic stem cell transplantation for myelofibrosis. Blood 102: 3912-3918, 2003.

9. Guardiola P, Anderson JE, Bandini G, Cervantes F, Runde V, Arcese W, Bacigalupo A, Przepiorka D, O'Donnell MR, Polchi P, Buzyn A, Sutton L, Cazals-Hatem D, Sale G, De Witte T, Deeg HJ and Gluckman E: Allogeneic stem cell transplantation for agnogenic myeloid metaplasia: a European Group for Blood and Marrow Transplantation, Societe Francaise de Greffe de Moelle, Gruppo Italiano per il Trapianto del Midollo Osseo, and Fred Hutchinson Cancer Research Center Collaborative Study. Blood 93: 2831-2838, 1999.
10. Ditschkowski M, Beelen DW, Trenschel R, Koldehoff M and Elmaagacli AH: Outcome of allogeneic stem cell transplantation in patients with myelofibrosis. Bone Marrow Transplant 34: 807-813, 2004.

11. Kroger N, Zabelina T, Schieder H, Panse J, Ayuk F, Stute N, Fehse N, Waschke O, Fehse B, Kvasnicka HM, Thiele J and Zander A: Pilot study of reduced-intensity conditioning followed by allogeneic stem cell transplantation from related and unrelated donors in patients with myelofibrosis. Br J Haematol 128: 690-697, 2005.

12. Horowitz MM, Gale RP, Sondel PM, et al: Graft-versusleukemia reactions after bone marrow transplantation. Blood 75: 555-562, 1990.

13. Mathe G, Amiel JL, Schwarzenberg L, Cattan A, Schneider M, Devries MJ, Tubiana M, Lalanne C, Binet JL, Papiernik M, Seman G, Matsukura M, Mery AM, Schwarzmann V and Flaisler A: Successful allogenic bone marrow transplantation in man: chimerism, induced specific tolerance and possible antileukemic effects. Blood 25: 179-196, 1965.

14. Kolb HJ, Schmid C, Barrett AJ and Schendel DJ: Graft-versusleukemia reactions in allogeneic chimeras. Blood 103: 767-776, 2004.

15. Kobayashi T, Hashimoto K, Matsumoto K, Yoshizaki K and Yoshikawa K: Analysis of the interleukin 6 receptor on normal human keratinocytes by digital imaging fluorescence microscopy. J Dermatol 20: 585-587, 1993.

16. Fehse B, Chukhlovin A, Kuhlcke K, Marinetz O, Vorwig O, Renges H, Kruger W, Zabelina T, Dudina O, Finckenstein FG, Kroger N, Kabisch H, Hochhaus A and Zander AR: Real-time quantitative Y chromosome-specific PCR (QYCS-PCR) for monitoring hematopoietic chimerism after sex-mismatched allogeneic stem cell transplantation. J Hematother Stem Cell Res 10: 419-425, 2001.

17. Thiele J, Wickenhauser C, Kvasnicka HM, Varus E, Schneider C, Muller $\mathrm{H}$ and Beelen DW: Mixed chimerism of erythro- and megakaryopoiesis following allogeneic bone marrow transplantation. Acta Haematol 109: 176-183, 2003.

18. Thiele J, Wickenhauser C, Kvasnicka HM, Varus E, Kleppe S, Beelen DW and Schaefer UW: Mixed chimerism of bone marrow $\mathrm{CD} 34^{+}$progenitor cells (genotyping, bcr/abl analysis) after allogeneic transplantation for chronic myelogenous leukemia. Transplantation 74: 982-986, 2002.

19. Elmaagacli AH, Peceny R, Steckel N, Trenschel R, Ottinger H, Grosse-Wilde H, Schaefer UW and Beelen DW: Outcome of transplantation of highly purified peripheral blood CD34+ cells with T-cell add-back compared with unmanipulated bone marrow or peripheral blood stem cells from HLA-identical sibling donors in patients with first chronic phase chronic myeloid leukemia. Blood 101: 446-453, 2003.

20. Wickenhauser C, Thiele J, Perez F, Varus E, Stoffel MS, Kvasnicka HM, Beelen DW and Schaefer UW: Mixed chimerism of the resident macrophage population after allogeneic bone marrow transplantation for chronic myeloid leukemia. Transplantation 73: 104-111, 2002.

21. Brown GM, Furlong RA, Sargent CA, Erickson RP, Longepied G, Mitchell M, Jones MH, Hargreave TB, Cooke HJ and Affara NA: Characterisation of the coding sequence and fine mapping of the human DFFRY gene and comparative expression analysis and mapping to the Sxrb interval of the mouse $\mathrm{Y}$ chromosome of the Dffry gene. Hum Mol Genet 7: 97-107, 1998.

22. Schiedlmeier B, Kuhlcke K, Eckert HG, Baum C, Zeller WJ and Fruehauf S: Quantitative assessment of retroviral transfer of the human multidrug resistance 1 gene to human mobilized peripheral blood progenitor cells engrafted in non-obese diabetic/ severe combined immunodeficient mice. Blood 95: 1237-1248, 2000.

23. Klein D, Bugl B, Gunzburg WH and Salmons B: Accurate estimation of transduction efficiency necessitates a multiplex real-time PCR. Gene Ther 7: 458-463, 2000.

24. Thiede C, Bornhauser M and Ehninger G: Strategies and clinical implications of chimerism diagnostics after allogeneic hematopoietic stem cell transplantation. Acta Haematol 112: 16-23, 2004.

25. Alizadeh M, Bernard M, Danic B, Dauriac C, Birebent B, Lapart C, Lamy T, Le Prise PY, Beauplet A, Bories D, Semana G and Quelvennec E: Quantitative assessment of hematopoietic chimerism after bone marrow transplantation by real-time quantitative polymerase chain reaction. Blood 99: 4618-4625, 2002. 
26. Kvasnicka HM, Wickenhauser C, Thiele J, Varus E, Hamm K, Beelen DW and Schaefer UW: Mixed chimerism of bone marrow vessels (endothelial cells, myofibroblasts) following allogeneic transplantation for chronic myelogenous leukemia. Leuk Lymphoma 44: 321-328, 2003.

27. Huss R, Deeg HJ, Gooley T, Bryant E, Leisenring W, Clift R, Buckner CD, Martin P, Storb R and Appelbaum FR: Effect of mixed chimerism on graft-versus-host disease, disease recurrence and survival after HLA-identical marrow transplantation for aplastic anemia or chronic myelogenous leukemia. Bone Marrow Transplant 18: 767-776, 1996.

28. Branch DR, Gallagher MT, Forman SJ, Winkler KJ, Petz LD and Blume KG: Endogenous stem cell repopulation resulting in mixed hematopoietic chimerism following total body irradiation and marrow transplantation for acute leukemia. Transplantation 34: 226-228, 1982 .

29. Bertheas MF, Lafage M, Levy P, Blaise D, Stoppa AM, Viens P, Mannoni $P$ and Maraninchi D: Influence of mixed chimerism on the results of allogeneic bone marrow transplantation for leukemia. Blood 78: 3103-3106, 1991.

30. Baron F and Sandmaier BM: Chimerism and outcomes after allogeneic hematopoietic cell transplantation following nonmyeloablative conditioning. Leukemia 20: 1690-1700, 2006.

31. Serrano J, Roman J, Sanchez J, Jimenez A, Castillejo JA, Herrera C, Gonzalez MG, Reina L, Rodriguez MC, Alvarez MA, Maldonado $\mathrm{J}$ and Torres A: Molecular analysis of lineagespecific chimerism and minimal residual disease by RT-PCR of p210(BCR-ABL) and p190(BCR-ABL) after allogeneic bone marrow transplantation for chronic myeloid leukemia: increasing mixed myeloid chimerism and p190(BCR-ABL) detection precede cytogenetic relapse. Blood 95: 2659-2665, 2000.

32. Smith A, Robson LG, Sharma P and Shaw PJ: Application of interphase FISH on direct bone marrow smears for evidence of chimerism in pediatric sex mismatched bone marrow transplantation. Pathology 31: 25-28, 1999.
33. Tamura S, Saheki K, Takatsuka H, Wada H, Fujimori Y, Okamoto T, Takemoto Y, Hashimoto-Tamaoki T, Furuyama J and Kakishita E: Early detection of relapse and evaluation of treatment for mixed chimerism using fluorescence in situ hybridization following allogeneic hematopoietic cell transplant for hematological malignancies. Ann Hematol 79: 622-626, 2000.

34. Clark RE, Dodi IA, Hill SC, Lill JR, Aubert G, Macintyre AR, Rojas J, Bourdon A, Bonner PL, Wang L, Christmas SE, Travers PJ, Creaser CS, Rees RC and Madrigal JA: Direct evidence that leukemic cells present HLA-associated immunogenic peptides derived from the BCR-ABL b3a2 fusion protein. Blood 98: 2887-2893, 2001.

35. Yakoub-Agha I, Saule P, Depil S, Micol JB, Grutzmacher C, Boulanger-Villard F, Bauters F, Jouet JP, Dessaint JP and Labalette M: A high proportion of donor CD4(+) T cells expressing the lymph node-homing chemokine receptor CCR7 increases incidence and severity of acute graft-versus-host disease in patients undergoing allogeneic stem cell transplantation for hematological malignancy. Leukemia 20: 1557-1565, 2006.

36. Thiede C, Lutterbeck K, Oelschlagel U, Kiehl M, Steudel C, Platzbecker U, Brendel C, Fauser AA, Neubauer A, Ehninger G and Bornhauser M: Detection of relapse by sequential monitoring of chimerism in circulating CD34 ${ }^{+}$cells. Ann Hematol 81 (Suppl. 2): S27-S28, 2002.

37. Chan L, Hardwick NR, Guinn BA, Darling D, Gaken J, GaleaLauri J, Ho AY, Mufti GJ and Farzaneh F: An immune edited tumour versus a tumour edited immune system: prospects for immune therapy of acute myeloid leukaemia. Cancer Immunol Immunother 55: 1017-1024, 2006.

38. Slavin S, Nagler A, Naparstek E, Kapelushnik Y, Aker M, Cividalli G, Varadi G, Kirschbaum M, Ackerstein A, Samuel S, Amar A, Brautbar C, Ben-Tal O, Eldor A and Or R: Nonmyeloablative stem cell transplantation and cell therapy as an alternative to conventional bone marrow transplantation with lethal cytoreduction for the treatment of malignant and nonmalignant hematologic diseases. Blood 91: 756-763, 1998. 